\title{
Co-Branding Dan Pengaruhnya Terhadap Brand Image
}

\author{
R. Pratama, B. Widjajanta \& G. Razati \\ Universitas Pendidikan Indonesia \\ rommy.pratama@student.upi.edu
}

\begin{abstract}
The purpose of this study was to determine the effect of Credit Problems and Profitability. The methodology of this research was carried out in a period of five years, for ten banks, in the framework of the research design used was historical data, for non-random samples using historical data, the design of this study used pooled design. This study uses a descriptive and verification approach with hypothesis testing methods and data analysis techniques using panel data regression. The findings of this study are Credit Problems affecting Profitability. The difference is determined in the independent variables, objects and research methods, population and research samples, research period, measurement tools and research results, as well as sources of theory and foreign journals and foreign books and research results.

\footnotetext{
ABSTRAK

Tujuan penelitian ini untuk mengetahui pengaruh Masalah Kredit dan Profitabilitas. Metodologi penelitian ini dilakukan dalam kurun waktu lima tahun, selama sepuluh bank, dalam rangka desain penelitian yang digunakan adalah data historis, terhadap sampel non-acak menggunakan data historis, maka desain penelitian ini menggunakan pooled Desain. Penelitian ini menggunakan pendekatan deskriptif dan verifikasi dengan metode uji hipotesis dan teknik analisis data menggunakan regresi data panel. Temuan penelitian ini adalah Kredit Masalah memengaruhi Profitabilitas. Perbedaannya ditentukan dalam variabel independen, objek dan metode penelitian, populasi dan sampel penelitian, periode penelitian, alat pengukuran dan hasil penelitian, serta sumber teori dan jurnal asing dan buku asing serta hasil penelitian.
}

\author{
ARTICLE INFO: \\ Article history: \\ Received 19 Desember 2016 \\ Revised 20 Desember 2016 \\ Accepted 22 Desember \\ 2016 \\ Available online $12 \mathrm{Mei}$ \\ 2017
}

\section{Keywords: \\ Brand Image, \\ Co-Branding}

\author{
Kata Kunci: \\ Brand Image, \\ Co-Branding
}

\section{PENDAHULUAN}

Pertumbuhan teknologi yang begitu tinggi telah menyebabkan kondisi pasar semakin dinamis, persaingan di antara produsen-produsen alat teknologi dan komunikasi khususnya pada industri smartphone semakin meningkat.

Salah satu buktinya dapat dilihat pada tahun 2013 Indonesia mempunyai 27,4 juta pengguna. Pada tahun 2015 pengguna aktif masih mengalami kenaikan sebesar 14 juta pengguna menjadi 52 juta pengguna aktif. (id.techinesia.com).

Indonesia menjadi pasar smartphone dengan pertumbuhan pengguna paling pesat. Hal ini dikarenakan pola konsumsi konsumen pada saat ini yang selalu menginginkan sebuah kemudahan dalam komunikasi yang dapat mendukung kegiatan mereka sehari-hari baik dalam pekerjaan maupun hal yang lainnya.
Banyaknya pengguna maka secara tidak langsung pendukung dari smartphone yaitu dalam hal ini operator semakin menjamur untuk mengakomodasi kebutuhan pengguna smartphone yang cukup tinggi. Dengan begitu pengguna smartphone dapat memilih operator sesuai dengan kebutuhan, dan tidak dibatasi oleh minimnya sarana pendukung smartphone.

Persaingan industri telekomunikasi yang semakin hari semakin ketat memaksa setiap operator melakukan kebijakan-kebijakan untuk menyelamatkan keberadaan perusahannya. Tak terkecuali dengan Axis, namun dengan banyaknya jumlah operator aktif yang berada di Indonesia membuat Axis tak mampu lagi bersaing dan mengalami kerugian yang cukup besar setiap tahunnya. Axis dihadapkan oleh dua pilihan sulit, yaitu Axis kemungkinan besar bangkrut atau selamat melalui merger atau akuisisi. 
Ini mengharuskan Axis mencari cara bagaimana agar perusahannya dapat bersaing kembali dengan empat operator besar lainnya, yakni Telkomsel, Indosat, XL, dan Tri. Merger adalah win win solution karena semua stakeholders diuntungkan. Pada tanggal 26 September 2013 akhirnya XL menandatangani perjanjian untuk mengakuisisi Axis.

Perusahaan telekomunikasi yang beroperasi di Indonesia menunjukkan persaingan yang sangat ketat. Hal ini dikarenakan perkembangan arus informasi yang meningkat drastis, sehingga dibutuhkan jasa telekomunikasi yang mampu memberikan kualitas layanan terbaik untuk memenuhi kebutuhan para pengguna jasa telekomunikasi di Indonesia. Setiap perusahaan telekomunikasi di Indonesia bersaing untuk memenangkan pangsa pasar yang ada dengan berusaha memberikan kualitas layanan terbaik yang dimiliki. Berikut adalah data market share pelaku industri operator seluler di Indonesia seperti yang dapat dilihat pada Tabel 1.1.

Tabel 1.1

Market Share Operator Seluler Tahun 2012-2015

\begin{tabular}{cccccc}
\hline No & Operator & $\mathbf{2 0 1 2}$ & $\mathbf{2 0 1 3}$ & $\mathbf{2 0 1 4}$ & $\mathbf{2 0 1 5}$ \\
\hline 1. & Telkomsel & 46.20 & $45.50 \%$ & $41.04 \%$ & $43.55 \%$ \\
& & $\%$ & & & \\
2. & Indosat & 22.10 & $24.70 \%$ & $22.01 \%$ & $21.00 \%$ \\
& $\%$ & & & \\
3. & XL Axiata & 23.00 & $21.90 \%$ & $26.00 \%$ & $25.05 \%$ \\
4 & Axis & $8.70 \%$ & $7,90 \%$ & $10.95 \%$ & $10.40 \%$ \\
\hline \multicolumn{5}{l}{ Sumber $:$ Hukumonline $(2015)$}
\end{tabular}

Berdasarkan Tabel 1.1 dapat dilihat market share dari masing-masing operator besar yang ada di Indonesia. Telkomsel masih menguasai market share ditahun 2015 sebesar $43.55 \%$ mengalami kenaikan dari tahun sebelumnya $41.04 \%$. Namun demikian market share Telkomsel masih tetap menguasai pasar operator seluler di Indonesia. Market share XL di tahun 2015 mengalami kenaikan $1,05 \%$ menjadi sebesar $27,05 \%$ berhasil mengungguli Indosat yang mempunya market share sebesar 23.00. Disini Axis pun mengalami kenaikan market share namun tidak cukup signitifkan, kenaikannya hanya $0,4 \%$ dibanding tahun sebelumnya $8,1 \%$ menjadi $9,2 \%$.

Persaingan dalam Industri komunikasi yang berkonsentrasi pada bidang operator seluler berdasakan merek mengalami fluktuasi setiap tahunnya. Banyaknya merek produk yang dikeluarkan oleh perusahaan-perusahaan komunikasi di Indonesia dalam hal ini operator seluler, menambah fakta begitu kuatnya persaingan yang ada di industri tersebut untuk menjadikan brand produk mereka menjadi yang terbaik (top brand) guna memperkuat dan memperluas bisnisnya. Top brand memberikan arti penting bagi kompetisi merek di pasar, karena top brand mampu memberikan ukuran kesuksesan sebuah merek di pasar. Berikut Tabel 1.2 merupakan data top brand index Simcard prabayar.

Tabel 1.2

Top Brand Index

Kategori Telekomunikasi Simcard Prabayar Tahun 2016

\begin{tabular}{clcccc}
\hline No & Merek & $\mathbf{2 0 1 4}$ & $\mathbf{2 0 1 5}$ & $\mathbf{2 0 1 6}$ & Top \\
\hline 1 & Simpati & $30.2 \%$ & $34.6 \%$ & $35.5 \%$ & TOP \\
2 & XL Prabayar & $16.7 \%$ & $14.1 \%$ & $14.8 \%$ & TOP \\
3 & IM3 & $16.9 \%$ & $14.0 \%$ & $15.4 \%$ & TOP \\
4 & Kartu As & $13.9 \%$ & $10.1 \%$ & $10.4 \%$ & \\
5 & Tri & $8.9 \%$ & $9.0 \%$ & $11.3 \%$ & \\
6 & Axis & $8.1 \%$ & $6.9 \%$ & $5.1 \%$ & \\
\hline \multicolumn{5}{l}{ Sumber : Top Brand Award $(2016)$}
\end{tabular}

Berdasarkan Tabel 1.2 dapat dilihat top brand index Axis pada 2014-2016. Pada tahun 2016, top brand index Axis mengalami penurunan sebesar $1,8 \%$ dari tahun sebelumnya yaitu $6.9 \%$. Simpati yang merupakan pesaing utama dari Axis mengalami peningkatan top brand index pada tahun 2016 sebesar 1.1\%, dari tahun sebelumnya $34.6 \%$. Sedangkan top brand index IM3 mengalami kenaikan pada tahun 2016 sebesar $1.4 \%$ dari tahun sebelumnya $14.0 \%$. XL sebagai perusahaan yang mengakuisisi Axis mengalami kenaikan top brand index sebesar $0.7 \%$.

Terjadinya penurunan nilai top brand index pada operator merek Axis kembali menunjukkan adanya permasalahan yang terjadi pada merek tersebut dan diindikasikan masalah tersebut berkaitan dengan cara pandang konsumen terhadap citra merek Axis. Menurut Burmann et al (2008), "Brand image is important determined of a buyer's behavior". Brand image merupakan determinasi penting dalam perilaku konsumen.

Setiap perusahaan pada dasarnya menginginkan brand image dari perusahaan mereka terus dapat dipertahankan bahkan ditingkatkan, termasuk pada operator Axis. Pada kondisi persaingan yang semakin sengit, hal tersebut tidaklah mudah untuk dilakukan. Perusahaan membutuhkan berbagai macam upaya untuk dapat mempertahankan brand image yang selama ini telah dibangun.

Perkembangan bisnis telekomunikasi dalam hal ini operator seluler membuat banyak perusahaan berlomba-lomba mengembangkan kualitas layanan mereka. Perkembangan tersebut diikuti oleh semakin banyaknya operator lain melakukan inovasi produk yang semakin bervariatif. Membangun brand image yang kuat merupakan strategi pemasaran yang tepat untuk mempertahankan konsumen yang perlu dilakukan oleh Axis ditengah sengitnya persaingan yang 
terjadi karena makin bervariatif nya strategi pemasaran merek lain.

PT. XL Axiata Tbk sebagai pemegang merek XL dan Axis melaksanakan berbagai program dan strategi guna mengahadapi persaingan dengan perusahaan lain. Dalam pelaksanaan program dan strategi pemasarannya perusahaan memfokuskan untuk memperkuat penyebaran arus informasi tentang kualitas terhadap merek Axis, dalam bentuk promosi maupun pengetahuan produk yang melibatkan konsumen sehingga lebih interaktif dan diharapkan dapat membantu meningkatkan penilaian konsumen terhadap merek XL.

Program pemasaran yang dilakukan oleh merek Axis dilakukan melalui media-media online seperti Facebook maupun media elektonik melalui iklan televisi. Selain itu, Axis sedang gencar melancarkan strategi dual-brand atau biasa disebut juga dengan co-branding pasca merger pada tahun 2014 lalu dengan XL. Namun demikian, peluncuran kembali merek Axis merupakan tindak lanjut dari proses merger dan akuisisi sebelumnya. Keputusan mempertahankan merek Axis untuk memberikan layanan yang lengkap kepada pelanggan, sesuai dengan kebutuhan masingmasing.

Penggabungan dua merek inilah yang menjadi strategi baru Axis dalam mempertahankan eksistensinya ditengah gempuran sengitnya persaingan dengan operator lain. Agar produknya semakin kuat dan saling melengkapi satu sama lain dalam memenuhi kebutuhan masyarakat. Dengan demikian salah satu kebijakan yang diambil oleh PT Axis Telekom Indonesia adalah dengan cara penggabungan dua merek atau disebut juga dengan co-branding. Co-branding merupakan format kerjasama antara dua atau lebih merek yang sudah memiliki pengakuan secara signitifkan dari costumer, dimana masing-masing partisipan memiliki brand yang sangat kuat. Biasanya cobranding terjalin dalam durasi medium dan longtern dan membangun potensi nilai yang saling berhubungan. Phillip Kotler (2010:322) mendefiniskan co-branding sebagai dua atau lebih merek yang dikenal dikombinasikan didalam penawaran, dimana atu sama lain saling memperkuat dan berharap dapat perhatian dari konsumen baru.

Menurut Washburn et al (2000) "Cobranding is a win/win strategy for both co-branding partners regardless of whether the original brands are perceived by consumers as having high or low brand equity. Although low equity brands may benefit most from co-branding, high equity brands are not denigrated even when paired with a low equity partner.

Co-branding merupakan upaya menguntungkan bagi kedua merek yang melakukan kerjasama. meskipun merek dengan citra yang rendah mendapatkan manfaat besar dari cobranding, merek dengan citra yang tinggi tidak akan berpengaruh bahkan ketika dipasangkan dengan merek yang mempunyai citra rendah.

Meski sekarang Axis dibawah naungan PT XL Axiata, tapi tim dalam setiap brand (Axis dan XL) dipisah sehingga mereka bisa lebih fokus untuk menggarap bisnisnya masing-masing dengan segmentasi pasar yang berbeda.

Menurut McCarthy dan Van Hoene (2014:1) "Co-branding deal, two or more companies come together and strategically nerge some of their own products, services, design, colour or logos to come up with a new marketable product or service."

Philip Kotler (2012:334) mendefinisikan co-branding sebagai dua atau lebih brand yang sudah dikenal dikombinasikan, dimana satu sama lain saling memperkuat dan berharap mendapat perhatian dari audiens baru.

Berdasarkan dari uraian permasalahan yang telah dikemukakan, maka perlu dilakukan penelitian mengenai "Pengaruh Co-branding Terhadap Brand image Operator Seluler Axis (Survey pada pengguna kartu Axis di media online facebook)".

Adapun tujuan penelitian ini adalah :

1. Memperoleh temuan mengenai gambaran pengaruh co-branding Axis dengan XL.

2. Untuk memperoleh temuan mengenai gambran brand image Axis.

3. Untuk memperoleh temuan megenai pengaruh co-branding terhadap brand image Axis.

\section{KAJIAN PUSTAKA}

Pemasaran merupakan salah satu kegiatan atau aktivitas penting yang dilakukan oleh perusahaan dalam usahanya untuk bertahan, berkembang dan tentunya untuk mendapatkan laba. Salah satu kegiatan pemasaran adalah memenuhi kebutuhan dan keinginan konsumen, serta berusaha bagaimana citra merek makin berkembang.

Kegiatan pemasaran merupakan faktor penting pada sebuah perusahaan dalam mempertahankan kelangsungan usaha yang dilakukan. Untuk memberikan gambaran yang lebih jelas mengenai pemasaran, berikut adalah pengertian pemasaran menurut para ahli. Terdapat pendapat beberapa ahli tentang konsep pemasaran.

Menurut George E. Belch dan Michael A. Belch (2007:8) "Pemasaran sebagai fungsi organisasi dan seperangkat proses untuk kreasi, komunikasi dan penyampaian nilai kepada para pelanggan dan mengelola hubungan pelanggan yang memberikan manfaat bagi organisasi dan para pemangku kepentingan (stakeholders) yang memiliki hubungan erat dengan organisasi." 
Menurut David L Kurtz (2008:7), "Pemasaran adalah fungsi organisasi dan sebuah proses untuk menciptakan, mengkomunikasikan, dan mengirimkan nilai untuk konsumen dan mengatur hubungan dengan konsumen sebagai cara menguntungkan perusahaan dan juga pihak berkepentingan.

Sedangkan menurut Lamb et al (2008:3), "Marketing is the activity, set of institutions, and processes for creating, communicating, delivering, and exchanging offerings that have value for customers, clients, partners, and society at large". Pemasaran adalah kegiatan, mengatur lembaga, dan proses untuk menciptakan, mengkomunikasikan, memberikan, dan bertukar penawaran yang memiliki nilai bagi pelanggan, klien, mitra, dan masyarakat pada umumnya.

Teori lain mengenai manajemen Pemasaran menurut Kottler dan Keller (2012:5) adalah, "The art and science of choosing target markets and getting, keeping, and growing customers through creating, delivering, and communicating superior customer value." Manajemen pemasaran merupakan seni dan pengetahuan dalam memilih target pasar, medapatkan, mempertahankan, dan menumbuhkan konsumen melalui menciptakan, menyampaikan, dan mengkomunikasikan nilai konsumen yang lebih unggul.

Menurut Kotler dan Amstrong (2012:8), "Pemasaran adalah seni dan pengetahuan dalam memilih target pasar dan membangun hubungan yang menguntungkan dengan konsumen".

Berdasarkan beberapa definisi yang dikemukakan oleh para ahli, maka dapat dikatakan bahwa pemasaran adalah suatu proses atau aktivitas untuk menciptakan, mengkomunikasikan, dan memberikan nilai kepada pelanggan melalui produk yang ditawarkan.

Menurut Gronholm (2012:5), indikator konsep pemasaran dapat dikelompokkan menjadi lima bagian, yaitu:

1. Marketing strategy

2. Marketing concept

3. Marketing research

4. Marketing segmentation

5. Marketing mix

Marketing mix merupakan konsep pemasaran yang sudah lama berkembang dan dipakai oleh berbagai kalangan dalam dunia bisnis. Konsep pemasaran marketing mix pada intinya memusatkan kemampuan perusahaan untuk menganalisis kebutuhan yang paling diharapkan oleh konsumen. Menurut Chong dalam Chai Lee Goi (2009), indikator marketing mix pada awalnya hanyalah price (harga). Namun pada perkembangannya, indikator marketing mxx berkembang menjadi 4P, yaitu price, place, product, promotion.
Menurut Kotler (2012:334) co-branding adalah pemasaran dengan menggabungkan produk mereka dengan produk dari perusahaan lain dengan berbagai cara. Dalam co-branding (penetapan merek bersama), disebut juga penetapan dua merek (dual branding) atau penguatan merek gabungan (brand bundling) dua atau lebih merek terkenal digabungkan menjadi satu produk bersama atau lebih merek terkenal digabungkan menjadi satu produk bersama atau dipasarkan bersama dalam beberapa cara.

Menurut Wei Lun Chang (2009:1) “Cobranding is a marketing arrangement to utilize multiple brand names on a single product or service. also, co brandiang can be seen as atype of strategic alliance between two parties." Cobranding adalah pengaturan pemasaran yang bertujuan untuk memanfaatkan beberapa nama merek pada suatu produk dan pelayanan. selain itu, co-branding juga dapat dilihat sebagi jenis strategi aliansi antara dua pihak atau lebih.

Menurut McCarthy dan Van Hoene (2014:3) "Co-branding deal, two or more companies come together and strategically nerge some of their own products, services, design, colour or logos to come up with a new marketable product or service." Dalam kesepakatan co-branding dua atau lebih perusahaan bersama sama melakukan kerjasama dengan menggabungkan produk mereka, pelayanan, bentuk, warna, atau logo untuk dijadikan sebuah merek baru berupa produk atau jasa.

Berdasarkan definisi dari beberapa para ahli diatas maka dapat disimpulkan bahwa cobranding adalah penggabungan antara dua merek atau lebih untuk memperkuat merek agar mendapat perhatian dari konsumen baru.

Menurut Dickinson dan Barker (2007:276) terdapat lima dimensi Co-branding yaitu:

\section{a. Familiarity \\ b. Product fit / co-brand match \\ c. Reputation \\ d. Attitude toward co-branding \\ e. Trust}

Saat ini banyak perusahaan yang berusaha memberi perhatian lebih kepada pembentukan brand image. Brand image dapat dijadikan referensi oleh konsumen dalam memberikan informasi mengenai merek atau produk yang ditawarkan oleh perusahaan. Menciptakan image merupakan tantangan tersendiri bagi sebuah perusahaan karena pembentukan image tidak dapat dilakukan dengan waktu yang singkat.

Brand image terbentuk melalui proses yang sangat kompleks dengan melibatkan perusahaan dan konsumen. Konsumen akan mengeluarkan timbal balik berupa penilaian kepada perusahaan apabila perusahaan tersebut dapat 
memneuhi apa yang konsumen inginkan. Apabila sebuah perusahaan memiliki image yang baik dimata konsumen maka perusahaan tersebut dapat dipastikan akan dapat bertahan ditengah sengitnya persaingan pada saat ini.

Shimp (2007:38) Brand image didasari oleh berbagai ketertarikan yang dikembangkan oleh konsumen pada setiap waktu, brand, seperti manusia dapat berupa gagasan yang mempunyai masing-masing personality

Supranto dan Limakrisna (2007:132) Brand image adalah apa yang konsumen pikir dan rasakan ketika mendengar atau melihat suatu merek dan apa yang konsumen pelajari tentang merek. Brand image disebut juga memori merek yang skematis, berisi interpretasi pasar sasaran tentang karakteristik produk, manfaat produk, situasi penggunaan dan karakteristik pemasaran.

Menurut Freddy Rangkuti (2008:20), brand image memiliki empat komponen utama yaitu:

1. Brand association (asosiasi merek)

2. Favorability of brand association (meningkatkan potensi merek)

3. Strength of association brand (kekuatan asosiasi merek)

4. Uniqueness of brand association (keunikan asosiasi merek)

Menurut Wijaya

(2011:16)

mengungkapkan bahwa brand image memiliki empat manfaat yaitu:

1. Functional benefits

2. Emotional benefits

3. Symbolic benefits

4. Social benefits

Para pemasar selalu mencari cara paling efektif dan efisien untuk memasarkan produknya baik berbentuk barang maupun jasa. Keterbatasan biaya operasional dari sebuah perusahaan membuat setiap perusahaan membutuhkan strategi yang jitu. Persaingan yang semakin kompetitif menjadi salah satu faktor yang membuat banyak perusahaan terpakasa harus menghentikan kegiatan operasionalnya karena ketidaksiapan dalam menghadapi persaingan.

Menurut Kotler dan Keller (2012:345)

"For co-branding to succeed, the two brands must separately have brand equity adequate brand awareness and a sufficiently positive brand image". Untuk menciptakan co-branding yang baik, dua merek secara terpisah harus memiliki ekuitas merek yang memadai dan citra merek yang bagus. Karena dengan begitu merek baru yang telah digabungkan akan mempunyai nilai atau citra lebih di mata konsumen sehingga akan memudahkan konsumen memilih merek tersebut.

Menurut Blackett dan Boad (2000) " $\mathrm{Co}$ branding reflects the true spirit of branding, which has to do with innovation and distinctiveness. It is a way to increase the scope and influence of brands, enter new markets, reduce costs through economies of scale and refresh a brand's image. For established brands, it offers the opportunity to create an entirely new income stream or to boost sales of existing products. For new brands, it may bring instant credibility in a normally sceptical marketplace."

Co-branding merupakan suatu inovasi yang mempunyai keunikan tersendiri. Ini merupakan salah satu cara untuk dapat meningkatkan pengaruh merek, memasuki pasar baru, mengurangi biaya melalui skala ekonomi dan menyegarkan citra merek. Untuk merek-merek mapan, co-branding menawarkan kesempatan untuk menciptakan arus pendapatan yang baru atau untuk mendongkrak penjualan produk yang ada. Untuk merek-merek baru, co-branding akan membawa dampak positif yang sudah terlebih dahulu diciptakan oleh merek sebelumnya. Dampaknya akan sangat bagus apabila merek baru dapat mengimbangi merek lama dalam hal co-branding.

Co-branding adalah fenomena lama dalam dunia pemasaran, dimana dua perusahaan atau lebih bergabung dan melakukan segala macam aktivitas untuk memberikan nilai tambah atas produk hasil co-branding tersebut.

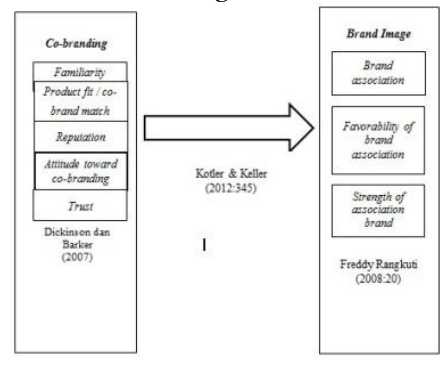

Gambar 2.1

Paradigma Penelitian

\section{METODE PENELITIAN}

Objek dalam penelitian ini adalah pengguna kartu operator Axis di media online Facebook. Dalam penelitian ini, paper menggunakan metode penelitian deskriptif dan verifikatif. Suharsimi Arikunto (2010:8) menjelaskan bahwa penelitian deskriptif merupakan penelitian yang bertujuan untuk memperoleh deskriptif tentang ciri-ciri variabel. Sedangkan penelitian verifikatif pada dasarnya ingin menguji kebenaran suatu hipotesis yang dilakukan melalui melalui pengumpulan data di lapangan.

Metode yang digunakan dalam penelitian ini adalah explanatory survey dengan teknik sample jenuh dan jumlah responden sebanyak 115 orang. Teknik analisis data yang digunakan dalam penelitian ini adalah regresi linier sederhana. 
Teknik pengumpulan data yang digunakan adalah studi kepustakaan, observasi, wawancara, kuesioner. Sedangkan teknik analisis data yang dilakukan adalah analisis deskriptif dan verifikatif.

\section{HASIL DAN PEMBAHASAN}

Hasil penelitian mengenai pengaruh $c o$ branding terhadap brand image operator seluler Axis di media online facebook Industri Bandung menghasilkan gambaran sebagai berikut:

Berdasarkan setiap dimensi co-branding, persentase tertinggi dari responden terhadap variabel co-branding terdapat pada dimensi product fit co-branding sebesar $87,92 \%$. Data tersebut menunjukkan bahwa kesamaan keunngulan Axis dan XL cukup baik, artinya masing-masing merek menyasar segmen yang berbeda sehingga menjadikan Axis dan XL unggul pada segmennya masing-masing. Sedangkan persentase terendah dari responden terhadap variabel co-branding terdapat pada dimensi reputation sebesar $84,42 \%$.

Berdasarkan setiap dimensi brand image. Indikator dengan persentase tertinggi terdapat pada dimensi brand association dengan persentase 95,97\%. dimensi brand association merupakan dimensi yang menjelaskan sejauh mana ingatan konsumen mengenal merek Axis. Sehingga dapat diartikan bahwa responden dapat mengenali Axis dengan baik, salah satunya berdasarkan keunikan promo yang dimiliki.

Dimensi dengan persentase terendah terdapat pada dimensi strength of association brand dengan persentase $85,25 \%$. Karena termasuk kedalam dimensi dengan persentase terendah, Axis perlu terus meningkatkan kekuatan merek di mata konsumen.

Berdasarkan hasil penelitian yang telah dilakukan, didapatkan hasil bahwa terdapat pengaruh antara co-branding terhadap brand image. Hal tersebut ditunjukkan dengan nilai korelasi (r) sebesar 0,350 yang berarti terdapat pengaruh antara co-branding dan brand image dalam kategori korelasi sedang. Hasil perhitungan koefisien determinasi menujukkan nilai sebesar $12,3 \%$ yang berarti perubahan brand image dipengaruhi sebesar 12,3\% oleh co-branding, sedangkan sisanya dipengaruhi oleh faktor lain diluar penelitian sebesar 87,7\%.

Pengujian hipotesis dilakukan dengan membandingkan hasil thitung dengan ttabel dengan perhitungan uji signifikansi $\alpha 0,05$ dengan derajat kebebasan $(\mathrm{dk})=\mathrm{n}-2,(\mathrm{dk})=115-2$ maka diperoleh $\mathrm{dk} 113$ atau 1,98 dari ttabel dengan taraf kesalahan $5 \%$. Penentuan hipotesis diterima apabila thitung > ttabel maka diperoleh hasil thitung > ttabel yaitu 3,974 > 1,98, maka dapat disimpulkan bahwa terdapat pengaruh positif antara co-branding terhadap brand image.
Pernyataan tersebut diperoleh melalui pengujian hipotesis dengan menggunakan metode regresi linier sederhana dan menghasilkan sebuah persamaan regresi ditunjukan dengan besar perubahan brand image $(\mathrm{Y})$ yang terjadi mengikuti perubahan co-branding (X) sebesar sebesar 53,175. Artinya bahwa jika tidak ada co-branding $(\mathrm{X}=0)$ maka brand image sebesar 53,175 satu satuan nilai.

Koefisisen regresi 0,301 satu satuan nilai artinya setiap terjadi peningkatan co-branding akan meningkatkan brand image sebesar 0,301 satu satuan nilai dan sebaliknya jika terjadi penurunan co-branding akan menurunkan brand image sebsar 0,301 satu satuan nilai. Koefisien determinasi sebesar $12,3 \%$, artinya brand image yang dapat dipengaruhi oleh co-branding (X) oleh persamaan regresi $\mathrm{Y}=53,175+0,301 \mathrm{X}$ adalah sebesar 12,3\%, sisanya sebesar $87,7 \%$ dipengaruhi faktor lain.

Berdasarkan hasil penelitian, membuktikan teori yang telah dipaparkan pada Bab II bahwa co-branding secara positif dapat mempengaruhi brand image pada operator Axis dan diduga kinerja co-branding juga dapat mempengaruhi brand image pada merek lainnya.

\section{KESIMPULAN DAN REKOMENDASI}

Berdasarkan hasil penelitian yang telah dilaksanakan dengan berdasarkan kepada uraian teori-teori dan pengujian analisis korelasi dan analisis regresi sederhana mengenai pengaruh $\mathrm{co}^{-}$ branding terhadap brand image Axis dapat disimpulkan bahwa co-branding secara keseluruhan memiliki pengaruh yang signifikan terhadap brand image Axis dengan perolehan nilai koefisien determinasi sebesar 12,3\% yang termasuk dalam kategori lemah. Sedangkan sisanya sebesar $87,7 \%$ dipengaruhi oleh faktor lain yang tidak diteliti dalam penelitian ini.

Penerapan co-branding yang dilakukan oleh Axis memiliki pengaruh yang signifikan, namun termasuk pada kategori lemah atau rendah. Hal ini menunjukkan perlu adanya perbaikan oleh perusahaan terhadap pelaksanaan strategi yang dilakukan saat ini, terutama dalam menciptakan reputation. Media sosial facebook dan website seharusnya perlu untuk ditingkatkan kinerjanya. Salah satu upaya yang dapat dilakukan adalah dengan meningkatkan daya tarik halaman media sosial facebook dengan lebih banyak aktif dalam melakukan interaksi dengan konsumen agar memudahkan konsumen dalah hal memilih ataupun memakai produk Axis. Sehingga dengan begitu reputasi Axis dapat menjadi lebih baik.

\section{DAFTAR PUSTAKA}

Arikunto, Suharsimi.2010. Prosedur Penelitian Suatu Pendekatan Praktik. Yogyakarta: Bina Aksara 
Belch, George. And Michael E. Belch. 2007. Advertising And Promotion, An Integrated Marketing Communications Perspective. New York: Mc Graw-Hill.

Blackett, Tom And Boad, Bob. 2000. CoBranding: The Science Of Alliance. London: Mcmillan Press. Ltd.

Boone, Louis E. And David L. Kurtz. 2008. Contemporary Marketing 13th Edition. South Western College.

Burmann, B And Evans, J.R 2008. Retail Management: A Strategic Approach. Pearson Publishers.

Chung, Wei Lung. 2009. Roadmap Of CoBranding Positions And Strategies. Taiwan. Tamkang University.

Dickinson S, And Barker A. 2007. Evaluations Of Branding Alliances Between NonProfit And Commercial Brand Partners: The Transfer Of Affect, International Journal Of Nonprofit And Voluntary Sector Marketing,

Goi, Chai Lee. 2009. A Review Of Marketing Mix: 4s Or More. International Journal Of Marketing Studies Vol 1. Malaysia. Curtin University Of Technology.

Gronholm, Taru. 2012. Marketing Concepts In Practise. Lahti University Of Applied Sciences.

Kotler, Philip And Gary Armstrong. 2012. Principles Of Marketing. New Jersey: Pearson

Lamb, Charles., Joe Hai, And Carl Mcdaniel. 2008. Marketing. Cengage Learning.

Mccarthy, Kelly And Samantha Von Hoene. 2014. Co-Branding: A Sweet Business Strategy. San Fransisco, Sideman \& Bancroft.
Rangkuti, Freddy. 2008. The Power Of Brands. Jakarta: Gramedia.

Shimp, Terence A. 2007, Integrated Marketing Communication In Advertising And Promotion Edisi Ketujuh. New York: Mcgrawhill.

Supranto, J Dan Limakrisna. 2007. Perilaku Konsumen Dan Strategi Pemasaran Untuk Memenangkan Persaingan Bisnis. Jakarta: Mitra Wacana Media.

Washburn, J. H., Till, B. D., \& Priluck, R. (2000). Co-Branding: Brand Equity And Trial Effects. Journal Of Consumer Marketing, 17(7), 591-604. 